\title{
Advanced control strategy of DFIG during symmetrical grid fault
}

\author{
Tariq Riouch $^{1}$, Cristian Nichita ${ }^{2}$ \\ ${ }^{1}$ ESTF, Technologies et Services Industriels Laboratory, USMBA University, Fez, Morocco \\ ${ }^{2}$ GREAH Laboratory, University Le Havre Normandy, Le Havre, France
}

\begin{tabular}{l} 
Article Info \\
\hline Article history: \\
Received Dec 22, 2020 \\
Revised Apr 5, 2021 \\
Accepted Jul 7, 2021 \\
\hline Keywords: \\
DFIG \\
Hybrid energy storage system \\
Voltage sag \\
Wind power fluctuation
\end{tabular}

\begin{abstract}
This article proposes a novel scheme to improve the doubly-fed induction generator (DFIG) behavior during grid fault. The DFIG's are sensitives to voltage variations when abrupt variations of the wind velocity arrive. For enhancing DFIG behavior, protecting the converters, and smoothing the fluctuations power output of the DFIG under sag voltage; a novel hybrid energy storage system scheme and its controller are proposed. The main advantages of our approach are a faster response and suppressing overvoltage on DC bus and globally less stress in the storage system. The control structure decreases the tiredness on the battery and restores the DC bus voltage rapidly, globally the battery system operating time increases. The results obtained by simulations in MATLAB validate the benefits of the suggested control.
\end{abstract}

This is an open access article under the CC BY-SA license.

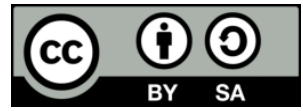

\section{Corresponding Author:}

Tariq Riouch

ESTF, Technologies et Services Industriels Laboratory

USMBA University, Fez, Morocco

Email: Tariq.riouch@gmail.com

\section{INTRODUCTION}

During the last decade the wind turbine (WT) integration in the grid has intensified, especially the DFIGs which is most used in WT farms. The DFIG is one of the WT systems most used in the wind farm, this due to several advantages; variable speed operation, sizing of the converters power represents only $25 \%$ $30 \%$ DFIG power and the decoupled reactive and active power control [1], [2]. In system of the DFIG, a stator winding is connected to the grid, but the winding rotor is interfaced with the electrical network by two power converters; converter associated with the rotor side (RSC), converter associated with the electrical grid (GSC) connected to network and the DC link, which connects these two converters. The RSC is using for controlling the decoupled powers (field orientation control). The GSC oversees the reactive power injected, and to stabilize the DC voltage. Several classical strategies controls were employed to control DFIGs systems; control by the direct power (DPC), vector controls (VC) and control by the direct torque (DTC) [3], [4].

During the fault in the electrical grid, the power system requires that DFIG must remain connected to network and contributed in the stability of the power systems. A sudden reduction voltage stator, a stator flux linkage could contain DC component. During voltage drop, DFIG is found exposed of two problems. First problem is: the transient current appearing in the coils of the rotor; Second problem is the DC bus overvoltage, that can cause performance degradation in DFIG system perturbing the global system behavior it could damage the power converters [5], [6]. With the increased DFIG penetration in electrical grid, performance of the DFIG and output power fluctuations injected under fault become research subjects [7].

The solutions presented to deal the low-voltage-ride-through divided in two groups: additional 
system solutions or improved control method. For the moderate voltage drop [8], the improved control strategies are used like stator current feedback control [9], demagnetization control [10], inductance emulating control (IEC) [11].

The auxiliary system solutions such as static synchronous compensators (STATCOM) [12], crowbar protection circuit using a resistance series [13], could solve a part of the LVRT capability problems [13]. Series grid side converter (SGSC) that it is detailed in [14], the dynamic voltage restorer (DVR) is studied in [15], superconducting magnetic energy storage and storage energy systems both are characterizing by highly efficient energy storage and power controllability under faults [16], [17] having a good result for enhancing the LVRT capacity. The strategies mentioned, act during the electrical grid fault during the sudden variation speed of the wind and remain inactive in the normal operation.

In this article, a new structure is suggested for enhancing behavior WT system based DFIG, reducing power fluctuation and improving LVRT capability. The model of DFIG WT and the hybrid energy storage system (HESS) are developed in MATLAB/Simulink; the simulation tests are performing to validate our proposed control. The paper is structured as behavior DFIG under fault with the overall system architecture of the HESS are discussed in second section. Stability study and controller of the HESS system are is studied in third section. Discussion with the simulations is given in fourth section, after you find the conclusion.

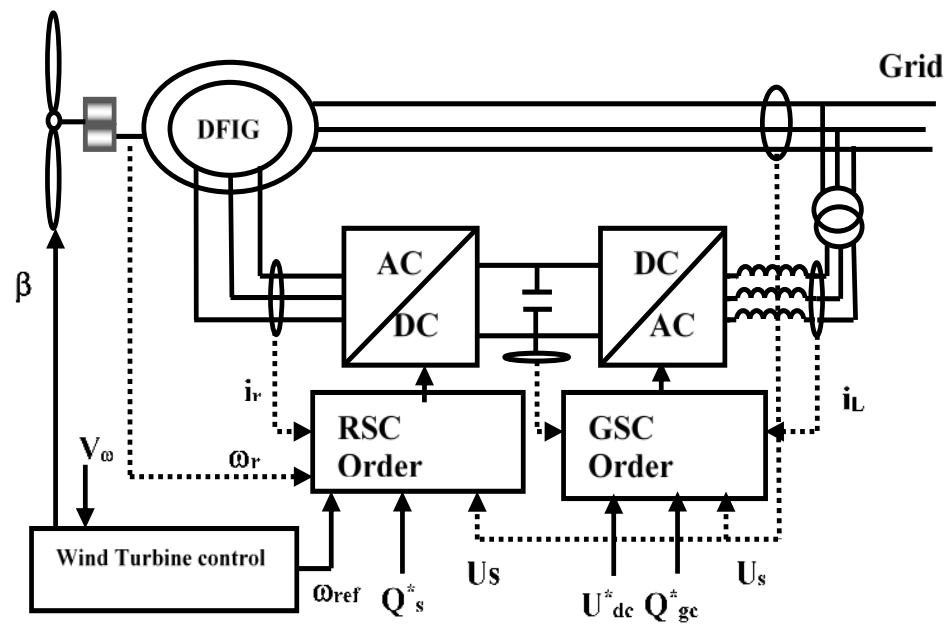

Figure 1. DFIG system

\section{DFIG SYSTEM UNDER VOLTAGE SAG}

\subsection{System model}

According to the Park model [18], the rotor variables is referred in the stator circuit are expressed by:

$$
\begin{aligned}
& \overrightarrow{\boldsymbol{v}}_{s}=\boldsymbol{R}_{s} \overrightarrow{\boldsymbol{\imath}_{s}}+\frac{d \vec{\psi}_{s}}{d t} \\
& \vec{v}_{r}=\boldsymbol{R}_{r} \overrightarrow{\boldsymbol{\imath}_{r}}+\frac{d \vec{\psi}_{r}}{d t}-j\left(\omega \vec{\psi}_{s}\right)
\end{aligned}
$$

While $\mathrm{i}, \mathrm{v}, \mathrm{R}, \psi$ and $\omega$ represents current, voltage, resistance, magnetic flux, and rotor electrical angular velocity, $\mathrm{s}$ and $\mathrm{r}$ designates the variables of the stator and the rotor.

In DFIG system, the coils stator has linked to the grid directly. The electrical grid determines the stator voltage $\mathrm{v}_{\mathrm{s}}$. The RSC regulates the rotor voltage $\mathrm{v}_{\mathrm{r}}$. The rotor and stator flux has Expressed with:

$$
\begin{aligned}
& \vec{\psi}_{s}=L_{m} \overrightarrow{\boldsymbol{l}_{r}}+L_{s} \overrightarrow{\boldsymbol{l}_{s}} \\
& \vec{\psi}_{r}=\boldsymbol{L}_{\boldsymbol{m}} \overrightarrow{\boldsymbol{l}_{\boldsymbol{s}}}+\boldsymbol{L}_{\boldsymbol{r}} \overrightarrow{\boldsymbol{l}_{r}}
\end{aligned}
$$


While a magnetizing inductance is denoted by $\mathrm{L}_{\mathrm{m}} . \mathrm{L}_{\mathrm{r}}$ and $\mathrm{L}_{\mathrm{s}}$ are the of the stator inductance and rotor inductance. Vr represents the rotor voltage; this is an important variable of the RSC. The rotor flux variation induces a rotor voltage, with (3), (4) is given by:

$$
\vec{\psi}_{r}=\frac{L_{m}}{L_{s}} \vec{\psi}_{s}+\sigma L_{r} \vec{l}_{r}, \quad \sigma=1-\frac{L_{m}^{2}}{L_{s} L_{r}}
$$

The leakage factor is designed by $\sigma$ and the transient inductance of the rotor is represented by $\sigma \mathrm{Lr}$.

With the formulas (5) and (2), we can obtain (6).

$$
\vec{v}_{r}=\left[\frac{L_{m}}{L_{s}} \cdot \frac{d \vec{\psi}_{s}^{r}}{d t}\right]-\left[R_{r} \vec{\imath}_{r}+\sigma L_{r} \frac{d \vec{\imath}_{r}}{d t}\right]
$$

The $\mathrm{Vr}$ formula represented in (6) shown two parts; first is an electromagnetic field (EMF), the second items are the voltage sag.

\subsection{Grid fault model of the DFIG}

During normal conditions, we can consider the stator resistance equal to zero, the flux of the stator can be presented by [19].

$$
\vec{\psi}_{s}^{s}=\frac{V_{s}}{j \omega_{s}} e^{j \omega_{s} t}
$$

While $\omega_{\mathrm{s}}$, Vs are the stator angular velocity and the stator voltage terminal. Then, using (6) the EMF is (8).

$$
\vec{e}_{r}=\frac{L_{m}}{L_{s}} \frac{d}{d t} \vec{\psi}_{s}^{r}=\frac{L_{m}}{L_{s}} s V_{s} e^{j \omega_{s r} t}
$$

While $\omega_{\text {sr }}, \mathrm{s}$ are slip angular frequency and slip. The slip s is proportional The EMF amplitude sVsLm/Ls to the. Under symmetrical voltage drop, the flux of the stator is given by [19], [20]:

$$
\vec{\psi}_{s}^{s}=\frac{V_{s}(1-p)}{j \omega_{s}} e^{j \omega_{s} t}+\frac{V_{s} p}{j \omega_{s}} e^{\frac{-t}{\tau_{s}}}
$$

While $\mathrm{p}, \tau_{\mathrm{s}}$ voltage sag depth and the stator flux time constant. A positive sequence component is shown by the first item, and the second part of the expression is the DC component. Using (6), the EMF can be expressed by (10):

$$
\vec{e}_{r}=-\frac{L_{m}}{L_{s}}\left[V_{s} p(1-s) e^{-j \omega_{r} t} e^{\frac{-t}{\tau_{s}}}-s V_{s}(1-p) e^{j \omega_{s r} t}\right]
$$

\section{HESS CONTROLLER APPROACHES}

The main circuit of DFIG and the additional HESS are showing in Figure 2. The DC link system contains RSC, GSC, DC chopper and HESS. The HESS energy system allows a barter of the real power in a short period [20], [21]. The HESS controller is used to enhance power flow regulation of a DFIG WT [22], [23]. The HESS system is based on the battery who takes care of fluctuations, and on Supercapacitor (SC) that deals with fast transitions. The proposed system and the control also improve also the battery lifetime. These advantages of this system approach are: i) faster response of the restoration DC link voltage; ii) less stress in storage system; iii) suppress overvoltage in DC link voltage. The HESS configuration represented in Figure 3, which include two energy storage systems: super-capacitor and battery. The HESS is linked to DFIG by its DC bus voltage.

While $\mathrm{v}_{\mathrm{sc}}$ and $\mathrm{v}_{\text {batt }}$ are the super capacitor voltage and battery voltage respectively, $\mathrm{L}_{\mathrm{sc}}$ and $\mathrm{L}_{\text {batt }}$ are inductor parameters of the SC and battery. $\mathrm{C}_{\mathrm{sc}}$ and $\mathrm{C}_{\mathrm{batt}}$ are the filter capacitance of SC and battery. $\mathrm{SW}_{\mathrm{a}}$, $\mathrm{SW}_{\mathrm{b}}, \mathrm{SW}_{\mathrm{c}}, \mathrm{SW}_{\mathrm{d}}$ and $\mathrm{SW}_{\mathrm{e}}$ are the switches of dc chopper. The $\mathrm{i}_{\text {batt }}$, $\mathrm{i}_{\mathrm{sc}}$ represent the battery currents and the $\mathrm{SC}$ currents. $\mathrm{V}_{\mathrm{dc}}$ is the voltage of the DC Bus. 


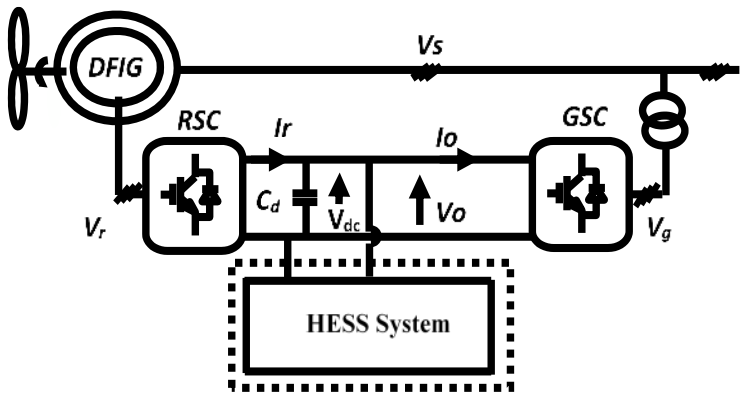

Figure 2. DFIG system using HESS

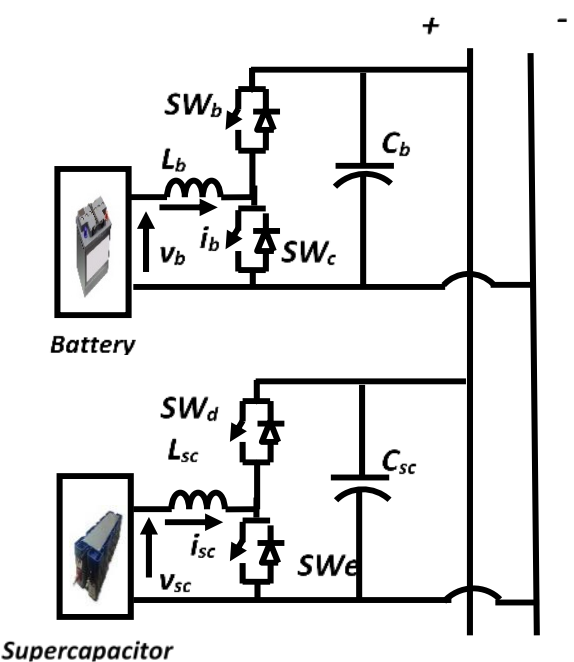

Figure 3. Architecture of proposed HESS

\subsection{Proposed control}

The controller adopted for the HESS system is shown in Figure 4. The main objectives are decreasing the tiredness on the battery and restoring the DC bus voltage rapidly, the operating time of the battery system increases [24]. During charge / discharge variation, the necessary power to balance and to smooth the flow of power in the DC bus is classified in two terms, (i) transient power (Ptr), and (ii) average power $(\mathrm{Pm})$. The power balance can be expressed:

$$
P_{G S C}(t)-P_{R S C}(t)=P_{b}(t)+P_{s c}(t)=\bar{P}_{m}+\hat{P}_{t r}
$$

Where, $\mathrm{P}_{\mathrm{sc}}(\mathrm{t}), \mathrm{P}_{\mathrm{b}}(\mathrm{t}), \mathrm{P}_{\mathrm{rsc}}(\mathrm{t})$ and $\mathrm{P}_{\mathrm{gsc}}(\mathrm{t})$ are $\mathrm{SC}$ power, battery power, rsc power a gsc power respectively.

For regulating the voltage of the DC link, the delivered HESS power is:

$$
\bar{P}_{m}(t)+\hat{P}_{t r}(t)=v_{d c} i_{T}
$$

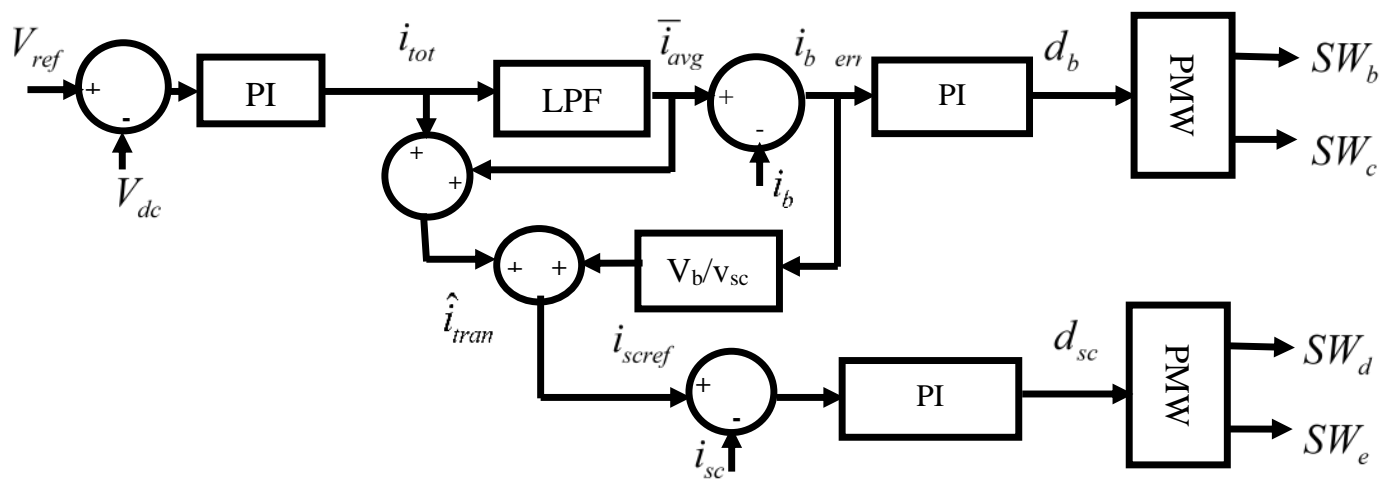

Figure 4. HESS controller system

The total current HESS system is:

$$
i_{T}(t)=\left(\frac{\bar{P}_{m}}{v_{d c}}\right)+\left(\frac{\bar{P}_{t r}}{v_{d c}}\right)=\bar{l}_{m}(t)+\hat{\imath}_{t r}(t)
$$

The voltage loop can be used to determine the total current:

$$
i_{T}(t)=\bar{\imath}_{m}(t)+\hat{\imath}_{t r}(t)=K_{p-v d c} v_{e r}+k_{i_{-} v d c} \int v_{e r} d t
$$


$\mathrm{K}_{\mathrm{p}_{-} \mathrm{vdc}}$ and $\mathrm{K}_{\mathrm{i}_{-} \mathrm{vdc}}$ are the integral and the proportional coefficient control loop of the DC link voltage, where $\mathrm{V}_{\text {ref }}, \mathrm{V}_{\mathrm{er}}$ and $\mathrm{V}_{\mathrm{dc}}$ represents reference, error, and measured of the DC bus voltage value respectively. Efficient total current sharing is required to achieve faster $\mathrm{V}_{\mathrm{DC}}$ recovery and an excellent performance. The average value of $i_{\mathrm{T}}$ is taking by LPF (15) give the average current:

$$
i_{\text {bref }}(s)=\bar{l}_{\text {avg }}(s)=\frac{\omega_{s}}{s+\omega_{s}} i_{T}(s)
$$

Where $i_{\text {bref }}(s)$ and $\omega_{c}$ are the reference current of the battery and cut-off frequency [25]. The battery system determines the average value of the current. The uncompensated power $\mathrm{P}_{\mathrm{b}_{-} \text {uncomp }}(\mathrm{s})$ is expressed by:

$$
P_{b-u n c o m p}(s)=-\left(i_{b}(s)-i_{b r e f}(s)\right) v_{b}(s)
$$

For raising performance of the super capacitor, the uncompensated power is used. The current controller for $\mathrm{SC}\left(\mathrm{i}_{\text {scref }}(\mathrm{s})\right)$ for $\mathrm{SC}$ is:

$$
i_{\text {scref }}(s)=\hat{\imath}_{t r}(s)+\left[\bar{l}_{m}(s)-i_{\text {batt }}(s)\right] \frac{v_{b}(s)}{v_{s c}(s)}
$$

The error between real current and the generated current of the battery with the supercapacitor reference currents is feeding to corrector (PI), and then the duty ration is generated. The method purpose is to regulate the DC voltage during the disturbed regime, thus to guarantee the power balance. The behavior of the HESS depends to the SC, the battery and RSC currents during the variation of the intermediate circuit voltage.

The small DC link voltage variation of the can be given as:

$$
\Delta v_{d c}=G_{b} \Delta i_{b}^{\prime}+G_{s c} \Delta i_{s c}^{\prime}+G_{r s c} \Delta i_{r s c}^{\prime}
$$

While $\Delta \mathrm{V}_{\mathrm{dc}}$ represent the DC voltage variation. $\mathrm{G}_{\mathrm{b}}, \mathrm{G}_{\mathrm{sc}}$ and $\mathrm{G}_{\mathrm{rsc}}$ are respectively the impedance signals of $\mathrm{SC}$, battery and RSC. $\Delta \mathrm{i}^{\prime}{ }_{\mathrm{sc}}, \Delta \mathrm{i}{ }^{\prime}$ batt and $\Delta \mathrm{i}^{\prime}{ }_{\text {rsc }}$ represents the currents variations of SC system, battery system and RSC system respectively.

\subsection{SC current loop}

The SC current function is expressed by:

$$
\begin{aligned}
& G_{o l_{-} s c}=G_{p i_{-} s c} G_{i d_{-} s c} H_{s c} \\
& G_{c l_{-} s c}=\frac{G_{p i \_s c} \cdot G_{i d \_s c}}{\left(1+G_{p i \_s c} \cdot G_{i d} s c \cdot H_{s c}\right)}
\end{aligned}
$$

While $\mathrm{G}_{\mathrm{cl} \_s c}$ and $\mathrm{G}_{\mathrm{ol} \_s c}$ represents closed loop and the open loop respectively. $\mathrm{K}_{\mathrm{i}_{\_} s c}$ and $\mathrm{K}_{\mathrm{p} \_s c}$ presents the integral and the proportional coefficient current controller of the SC. $\mathrm{H}_{\mathrm{sc}}$ is the super capacitor current gain of the control loop feedback. The SC current bode plot on open loop is presented in Figure 5 (a). The SC current controller parameters are determined by SISO toolbox: $\mathrm{K}_{\mathrm{p}_{-} \mathrm{sc}}=0.25$ and $\mathrm{K}_{\mathrm{i} \_s c}=180$.

\subsection{Battery current loop}

The battery open loop $\left(\mathrm{G}_{\mathrm{ol} \_} \mathrm{b}\right)$ is given by:

$$
G_{o l \_b}=G_{p i \_b} G_{i d \_b} H_{b}
$$

In Table $1 \mathrm{~K}_{\mathrm{i} \_\mathrm{b}}, \mathrm{K}_{\mathrm{p} \_\mathrm{b}}$ represents the battery current integral and the battery current proportional coefficient respectively of the corrector. $\mathrm{H}_{b}$ is the gain feedback of the control loop current of the battery designed in (21). The battery current bode plot is presented in Figure 5 (b). The parameters controller is determined by SISO toolbox: $\mathrm{K}_{\mathrm{p} \_\mathrm{b}}=0.53$ and $\mathrm{K}_{\mathrm{i} \_\mathrm{b}}=120$. 


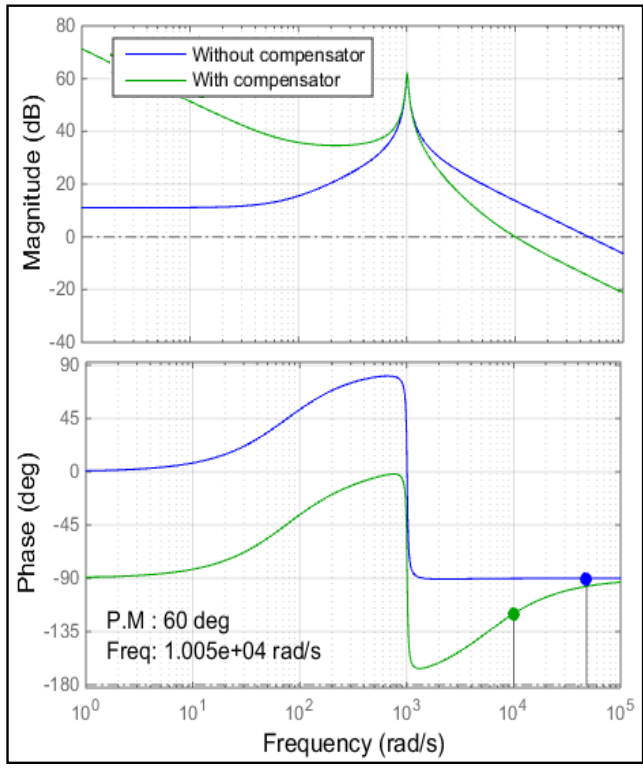

(a)

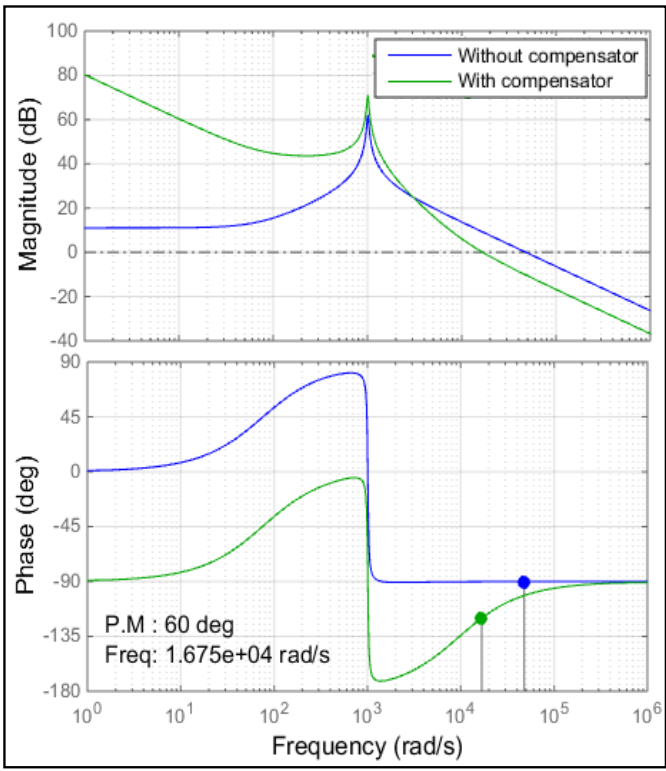

(b)

Figure 5. (a) SC current control Bode plot and (b) battery current control Bode plot

Table 1. Transfers functions of the HESS system

\begin{tabular}{ll}
\hline Duty Cycle of the SC inductor current & $G_{i d_{-} s c}=\frac{\bar{i}_{s c}}{d_{s c}}=\frac{\left(\mathrm{C}_{\mathrm{sc}} v_{d c}\right) s+2\left(1-d_{s c}\right) i_{L}}{\left(L_{s c} \mathrm{C}_{\mathrm{sc}}\right) s^{2}+\frac{L_{s c}}{R} s+\left(1-d_{s c}\right)^{2}}$ \\
SC current to output voltage & $G_{i v_{-} s c}(s)=\frac{\hat{v}_{d c}}{\hat{i}_{s c}}=\frac{\left(1-d_{s c}\right) v_{d c}-\left(L_{s c} i_{L}\right) s}{\left(\mathrm{C}_{s c} v_{d c}\right)+2\left(1-d_{s c}\right) i_{L}}$ \\
Duty Cycle of the battery inductor current & $G_{i_{-} s c}(s)=\frac{i_{b}}{d_{b}}=\frac{\left(c_{b} v_{d c}\right) s+2\left(1-d_{b}\right) i_{L}}{\left(L_{b} C_{b}\right) s^{2}+\frac{L_{b}}{R} s+\left(1-d_{b}\right)^{2}}$ \\
SC corrector & $G_{p i_{-} s c}(s)=K_{p_{-} s c}+\left(\frac{K_{i_{-} s c}}{s}\right)$ \\
Battery corrector & $G_{p i_{-} b}(s)=K_{p_{-} b}+\left(\frac{K_{i_{-} b}}{s}\right)$ \\
DC Bus voltage corrector & $G_{p i_{-} v d c}(s)=K_{p_{-} v d c}+\left(\frac{K_{i_{-} v d c}}{s}\right)$
\end{tabular}

\section{SIMULATIONS AND DISCUSSIONS}

For validate the effectiveness the suggested system, the DFIG system with the HESS design is established in MATLAB/Simulink, for checking the effectiveness of the suggested scheme, a wind farm is used, it is consisting of six DFIG system, Table 2 shows the elements of each DFIG. The wind speed variation and the sag voltage are shown in Figure 6 and Figure 7. The Figure 8 show the rotor winding current with the traditional scheme under sag voltage. With the suggested system, the peak of the rotor current has been decreased show Figure 9. With HESS into DFIG system, the active power injected into the network becomes more smoothen with Figure 10, precisely between the two moments $t_{1}=0.8 \mathrm{~s}$ and $t_{2}=1.4 \mathrm{~s}$. 
Table 2. Parameters used for the simulation

\begin{tabular}{lll}
\hline Element & \multicolumn{1}{c}{ Designation } & \multicolumn{1}{c}{ values } \\
\hline $\mathrm{DFIG}$ & Power & $6 \times 1,5 \mathrm{MW}$ \\
$\mathrm{V}_{\mathrm{s}}$ & Stator voltage & $690 \mathrm{~V}$ \\
$\mathrm{R}_{\mathrm{s}}$ & Resistance of the stator coils & $0.0048 \mathrm{~m} \Omega$ \\
$\mathrm{L}_{\mathrm{s}}$ & Inductance of the stator coils & $0.1386 \mathrm{mH}$ \\
$\mathrm{R}_{\mathrm{r}}$ & Resistance of the rotor coils & $0.00549 \mathrm{~m} \Omega$ \\
$\mathrm{L}_{\mathrm{r}}$ & Inductance of the rotor coils & $0.1493 \mathrm{mH}$ \\
$\mathrm{f}$ & Frequency & $50 \mathrm{~Hz}$ \\
$\mathrm{~V}_{\mathrm{dc}}$ & DC voltage & $1150 \mathrm{~V}$ \\
$\mathrm{Cd}$ & Capacitor of the dc link & $10 \mu \mathrm{F}$ \\
$\mathrm{fs}$ & Switching frequency & $10 \mathrm{KHZ}$ \\
\hline
\end{tabular}

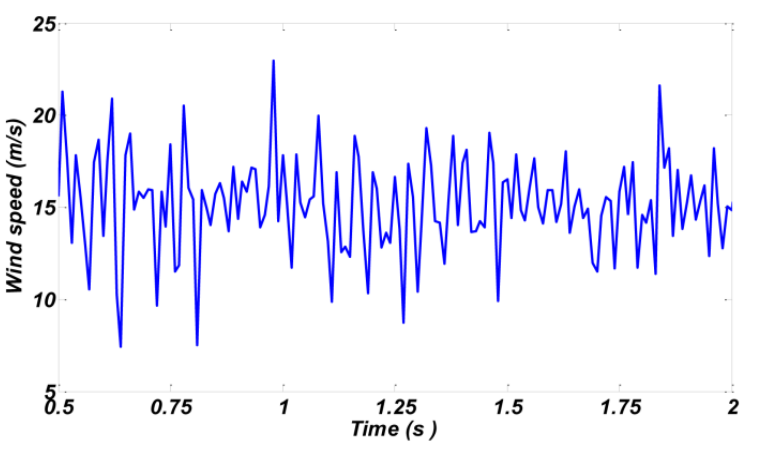

Figure 6. Wind speed evolution

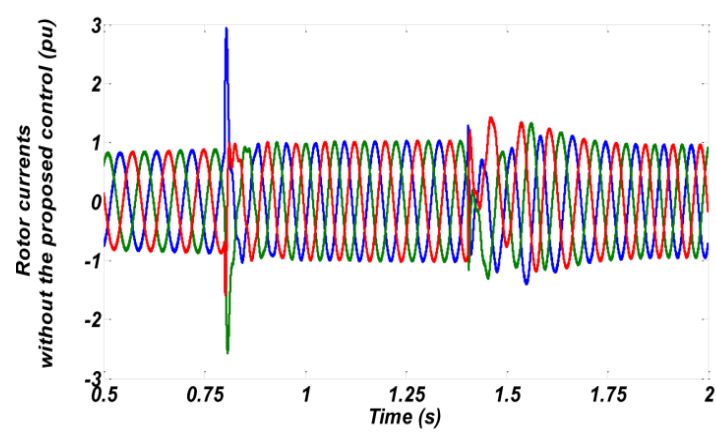

Figure 8. Rotor current without HESS strategy

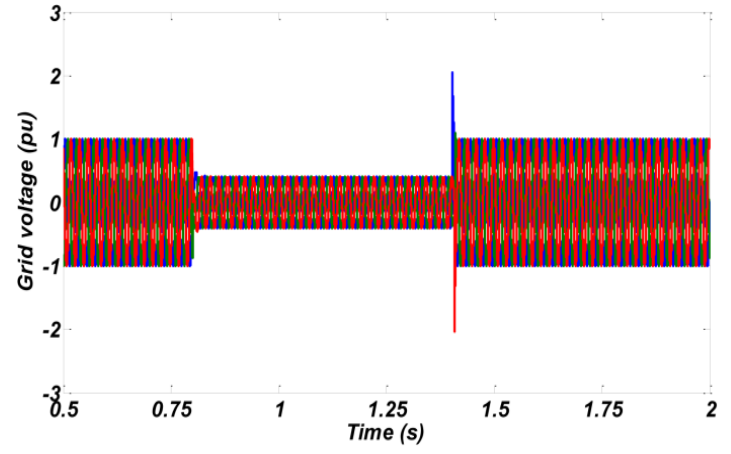

Figure 7. Grid voltage

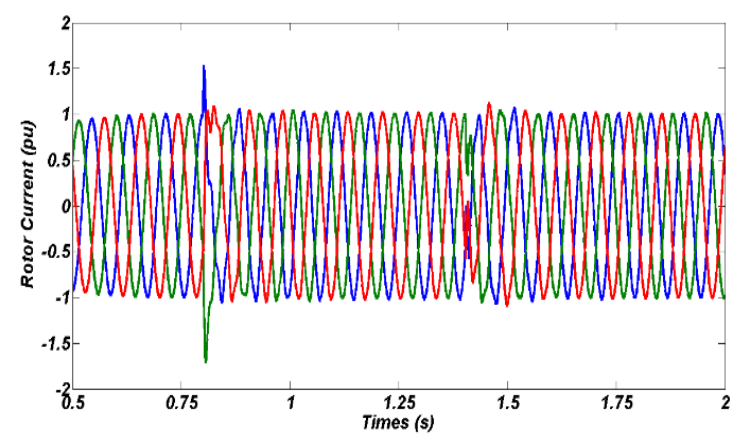

Figure 9. Rotor current with the HESS strategy

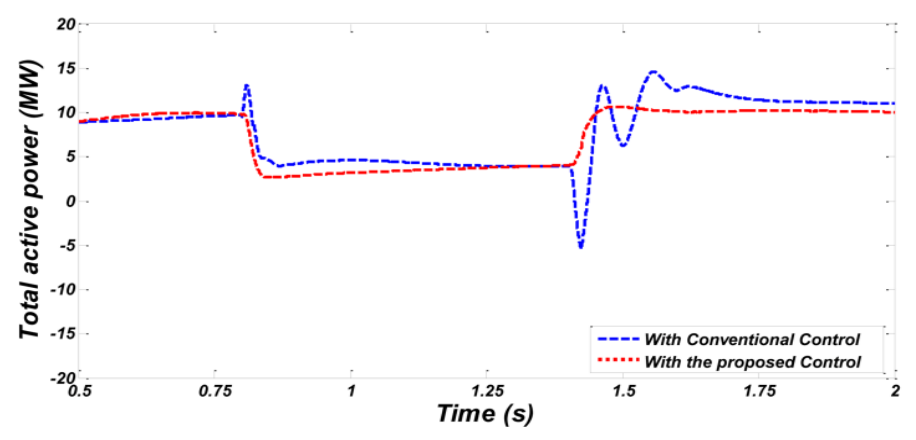

Figure 10. Real power

The curve of a reactive power obtained by the suggested is kept around zero with the HESS system Figure 11. The DC voltage overshoot is shown in Figure 12, the voltage drop causes an overvoltage peak, which reaches 1425 with the traditional system as it is shown, and this voltage value can cause a material 
damage, with the proposed system this peak has disappeared. During a symmetrical voltage dip, the performances of the DFIG with the traditional system and the proposed system are evaluated. The simulations carried out with or without the HESS system show that the effectiveness of the results, which made it possible to improve the behavior of the DFIG while protecting it.

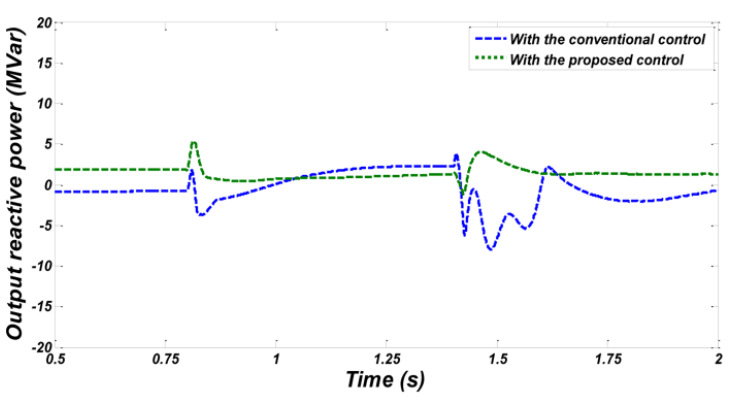

Figure 11. Reactive power

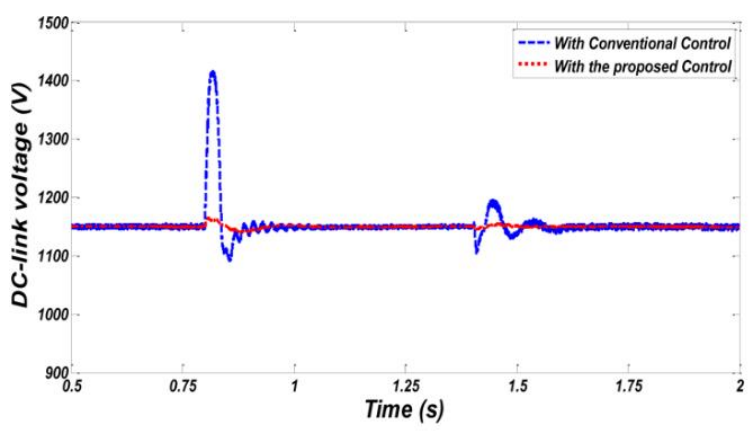

Figure 12. DC-link voltage

\section{CONCLUSION}

A new control scheme for wind turbine based DFIG systems, which a HESS and it control are employed to improve the DFIG system behavior, has been evalued. The proposed system is beneficial to improve the behavior of the DFIG system, and offer a best transient performance under a disturbed regime. The results of the simulation shows that the Hybrid Energy Storage System can smooth rapidly the active power fluctuations, keep reactive power around zero and the same time reducing the voltage variation of the intermediate circuit. To have a broad view, our future work will deal with the proposed system during an asymmetric fault.

\section{REFERENCES}

[1] S. Hu, X. Lin, Y. Kang, and X. Zou, "An improved low-voltage ridethrough control strategy of doubly fed induction generator during grid faults," IEEE Transactions on Power Electronics, vol 26, pp. 3653-3665, December 2011, doi: 10.1109/TPEL.2011.2161776.

[2] J. Liang, W. Qiao, and R. G. Harley, "Feed-forward transient current control for low-voltage ride-through enhancement of DFIG wind turbines," IEEE Transactions on energy Conversion, vol. 25, pp. 836-843, Septembre 2010, doi: 10.1109/TEC.2010.2048033.

[3] T. Riouch, R. El-Bachtiri, and M. Salhi, "Robust sliding mode control for smoothing the output power of DFIG under fault grid," International Review on Modelling and Simulations, vol.6, pp. 1264-1270, August.

[4] E. Tremblay, S. Atayde, and A. Chandra, "Comparative study of control strategies for the doubly fed induction generator in wind energy conversion systems: A DSP-based implementation approach," IEEE Transactions Sustainable Energy, vol. 2, no. 3, pp. 288-299, July 2011, doi: 10.1109/TSTE.2011.2113381.

[5] W. Guo, L. Xiao, and S. Dai, "Enhancing low-voltage ride-through capability and smoothing output power of DFIG with a superconducting fault-current limiter-magnetic energy storage," IEEE Transactions Energy conversion, vol. 27, no. 2, pp. 277-295, June 2012, doi: 10.1109/TEC.2012.2187654.

[6] T. Riouch, and R. El-Bachtiri, "Advanced control strategy of doubly fed induction generator based wind-turbine during symmetrical grid fault," International Review of Electrical Engineering, vol 9, pp. 829-834, 2014, doi: 10.15866/iree.v9i4.2306.

[7] T. Riouch, R. EL-Bachtiri, A. Alamery, and C. Nichita, "Control of battery energy storage system for wind turbine based on DFIG during symmetrical grid fault," in International Conference on Renewable Energies and Power Quality, 2015, pp. 714-718, doi: 10.24084/repqj13.465.

[8] X.-Y. Xiao, R.-H. Yang, Z.-X. Zheng, and Y. Wang, "Cooperative rotor-side SMES and transient control for improving the LVRT capability of grid-connected DFIG-based wind farm," IEEE Transaction on Applied Superconductivity, vol. 29, pp. 1-5, March 2019, doi: 10.1109/TASC.2018.2881315.

[9] F. K. A. Lima, A. Luna, P. Rodriguez, E. H. Watanabe, and F. Blaabjerg, "Rotor voltage dynamics in the doubly fed induction generator during grid faults," IEEE Transactions Power Electroncs, vol. 25, pp. 118-130, Jan. 2010, doi: 10.1109/TPEL.2009.2025651.

[10] D. Xiang, L. Ran, P. J. Tavner, and S. Yang, "Control of a doubly fed induction generator in a wind turbine during grid fault ride-through," IEEE Transaction Energy Conversion, vol. 21, no. 3, pp. 652-662, Sept. 2006, doi: 10.1109/TEC.2006.875783. 
[11] Q. Huang, X. Zou, D. Zhu, and Y. Kang, "Scaled current tracking control for doubly fed induction generator to ride-through serious grid faults," IEEE Transactions Power Electroncs, vol. 31, no. 3, pp. 2150-2165, March 2016, doi: 10.1109/TPEL.2015.2429153

[12] Y. K. Gounder, D. Nanjundappan, and V. Boominathan, "Enhancement of transient stability of distribution system with SCIG and DFIG based wind farms using STATCOM," IET Renewable Power Generation, vol. 10, no. 8, pp. 1171-1180, Sept. 2016, doi: 10.1049/iet-rpg.2016.0022.

[13] M. M. Hossain, and M. H. Ali, "Transient stability improvement of doubly fed induction generator based variable speed wind generator using DC resistive fault current limiter," IET Renewable Power Generation, vol. 10, no. 2, pp. 150-157, 2016, doi: 10.1049/iet-rpg.2015.0150.

[14] P. S. Flannery, and G. Venkataramanan, "Unbalanced voltage sag ride-through of a doubly fed induction generator wind turbine with series grid-side converter," IEEE Transactions on Industry Applications, vol. 45, no. 5, pp.18791887, Sept.-oct. 2009, doi: 10.1109/TIA.2009.2027540

[15] D. Ramirez, S. Martinez, C. A. Platero, F. Blazquez, and R. M. de Castro, "Low-voltage ride-through capability for wind generators based on dynamic voltage restorers," IEEE Transactions Energy Conversion, vol. 26, pp. 195-203, March 2011, doi: 10.1109/TEC.2010.2055869.

[16] J. Shi, Y. Tang, Y. Xia, L. Ren, and Jingdong Li, "SMES based excitation system for doubly-fed induction generator in wind power ap-plication," IEEE Transactions on Applied Superconductivity, vol. 21, no. 3, pp. 11051108, Jun 2011, doi: 10.1109/TASC.2011.2105450.

[17] A. Abu-Siada, and S. Islam, "Application of SMES unit in improving the performance of an AC/DC power system," IEEE Transactions on Sustainable Energy, vol. 2, no. 2, pp. 109-121, 2011, doi: 10.1109/TSTE.2010.2089995.

[18] J. Lopez, P. Sanchis, X. Roboam, and L. Marroyo, "Dynamic behavior of the doubly-fed induction generator during three-phase voltage dips," IEEE Transactions Energy Conversion, vol. 22, no. 3, pp. 709-717, Sep. 2007, doi: 10.1109/TEC.2006.878241

[19] S. Xiao, G. Yang, H. Zhou, and H. Geng, "A LVRT control strategy based on flux linkage tracking for DFIG-based WECS," IEEE Transaction Industrial Electronics, vol. 60, no. 7, pp. 2820-2832, 2013, doi: 10.1109/TIE.2012.2205354.

[20] T. Riouch, and R. El-Bachtiri, "Enhanced the DFIG system behavior under symmetrical sag voltage," Journal of Theoretical and Applied Information Technology (JATIT), vol. 99, no.10, pp. 2206-2215, 31st May 2021.

[21] Q. Xu, J. Xiao, P. Wang, X. Pan, and C. Wen, "A decentralized control strategy for autonomous transient power sharing and state-of-charge recovery in hybrid energy storage systems," IEEE Transactions on Sustainable Energy, vol. 8, no. 4, pp. 99, pp. 1443-1452, 2017, doi: 10.1109/TSTE.2017.2688391.

[22] S. Kolluri, "Application of distributed superconducting magnetic energy storage system (D-SMES) in the entergy system to improve voltage stability," in IEEE Power Engineering Society Winter Meeting. Conference Proceedings. vol. 2, pp. 838-841, 2002, doi: 10.1109/PESW.2002.985123.

[23] M. Ross, M. Borodulin, and Y. Kazachkov, "Using D-SMES devices to improve the voltage stability of a transmission system," in 2001 IEEE/PES Transmission and Distribution Conference and Exposition. Developing New Perspectives (Cat. No.01CH37294), vol. 2, pp. 1144 -1148, 2001, doi: 10.1109/TDC.2001.971419.

[24] H. Zhou, T. Bhattacharya, D. Tran, T. S. T. Siew, and A. M. Khambadkone, "Composite energy storage system involving battery and ultracapacitor with dynamic energy management in microgrid applications," IEEE Transactions on Power Electronics, vol. 26, no. 3, pp. 923-930, Mar, 2011, doi: 10.1109/TPEL.2010.2095040.

[25] M. Hamzeh, A. Ghazanfari, Y. A.-R. I. Mohamed, and Y. Karimi, "Modeling and design of an oscillatory currentsharing control strategy in dc microgrids," IEEE Transactions on Industrial Electronics, vol. 62, no. 11, pp. 66476657, Nov. 2015, doi: 10.1109/TIE.2015.2435703. 